\title{
HEALTH BEHAVIOR ASSOCIATED WITH QUALITY OF LIFE AMONG ELDERLY WITH HYPERTENSION
}

\author{
Hari Peni Julianti, Aras Utami, Diah Rahayu Wulandari \\ Department of Public Health-Preventive Medicine, Faculty of Medicine, \\ Universitas Diponegoro
}

\begin{abstract}
Background: The quality of life of elderly people has become increasingly important with the demographic shift to greying population. Quality of life is defined by personal feelings, details, outlook, and day-to-day experiences, which include how happy and positive one feels, how comfortable and secure, how productive and desired, how healthy and free an individual considers themselves, etc. This study aimed to determine health behavior associated with quality of life among elderly with hypertension.

Subjects and Method: This was a cross sectional study conducted at Puskesmas (community health center) Rowosari, Semarang, Central Java. A sample of 62 elderly with hypertension was selected for this study by simple random sampling. The dependent variable was quality of life. The independent variables were adherence to treatment, physical exercise, diet, and smoking. Quality of life was measured by Short Form-36. Dietary pattern was measured by food recall. The other data were collected by questionnaire. The data were analyzed by chi square with prevalence ratio (PR) as the measure of association.

Results: Adherence to treatment $(\mathrm{PR}=10.27$; CI $95 \%=2.85$ to $36.94 ; \mathrm{p}<0.001)$, physical exercise $(\mathrm{PR}=12.00$; $\mathrm{CI} 95 \%=2.26$ to $63.86 ; \mathrm{p}=0.001)$, good diet $(\mathrm{PR}=$ $1.80 ;$ CI $95 \%=1.40$ to $2.34 ; \mathrm{p}=0.001)$, and smoking abstinence $(\mathrm{PR}=3.36 ; \mathrm{CI}$ $95 \%=1.04$ to $10.90 ; p=0.038$ ) were associated with better quality of life in elderly with hypertension.

Conclusion: Adherence to treatment, physical exercise, good diet, and smoking abstinence are associated with good quality of life in elderly with hypertension.
\end{abstract}

\section{Correspondence:}

Hari Peni Julianti. Department of Public Health-Preventive Medicine, Faculty of Medicine, Universitas Diponegoro, Semarang, Central Java.

Email: hari_peni@yahoo.com. Mobile: 081326381347 